\title{
Results of preoperative electrical stimulation of pelvic floor muscles in the continence status following radical retropubic prostatectomy
}

Carla Elaine Laurienzo, Carlos Alberto Ricetto Sacomani, Telma Ribeiro Rodrigues, Stênio de Cássio Zequi, Gustavo Cardoso Guimarães, Ademar Lopes

Department of Physiotherapy (CEL, TRR), Department of Pelvic Surgery (CARS, SCZ, AL) and Department of Urology (GCG), A.C. Camargo hospital, Antonio Prudente foundation, Sao Paulo, Brazil

\section{ABSTRACT}

Purpose: To evaluate preoperative rectal electrical stimulation in the recovery of urinary continence in patients who undergo radical retropubic prostatectomy.

Materials and Methods: Patients were divided into 3 randomized groups: control, pelvic exercises, and electrical stimulation. A 1 hour pad-test, the ICIQ-SF, and the SF-36 were performed 1, 3, and 6 months after the surgical procedure.

Results: Of the 58 patients who were initially included in the study, 9 were excluded due to radiotherapy after surgical intervention, an indwelling urethral catheter for more than 30 days, high surgical risk, loss of follow-up, or incomplete participation in the study routines and spontaneous interruption. Forty-nine patients concluded the study (15 in the control group, 17 in the exercise group, and 17 in the electrical stimulation group). We did not observe any significant difference in the pad test $(p>0.05)$, the 8 domains of the SF-36, or ICIQ-SF score compared with control groups (control, exercise, and electrical stimulation).

Conclusion: Preoperative rectal electrical stimulation has no impact on continence status in patients who undergo radical retropubic prostatectomy. There is no difference in the three above mentioned groups with regard to urinary leakage and quality of life.

\section{ARTICLE INFO}

\section{Key words:}

Neoplasms; Prostatectomy;

Urinary Incontinence; Pelvic

Floor; Quality of Life

Int Braz J Urol. 2013; 39: 182-8

Submitted for publication:

April 24, 2012

Accepted after revision:

January 10, 2013

\section{INTRODUCTION}

Radical retropubic prostatectomy (RPP) is the chief option in the treatment of prostate cancer. Although it is a routine procedure that has improved with regard to technique, urinary incontinence (UI) remains a significant condition $(1,2)$. Despite total urinary control, the majority of patients experiences some period of UI following surgery (2). Because UI negatively affects quality of life and can delay a return to social and professional activities (3), patients desire a rapid recovery of continence.
Several studies have described various modalities of pelvic floor muscle rehabilitation (PFMR), including Kegel exercises with or without biofeedback and electrical stimulation post-RPP $(2,4-6)$. PFMR can enhance the return of urinary control after RPP. Some groups have conducted PFMR preoperatively and postoperatively (7), but few have analyzed the impact of PFMR that is performed exclusively before the procedure $(8,9)$. PFMR has been hypothesized to prepare the urethral sphincter mechanism and pelvic floor muscles preoperatively, which remains to be demonstrated. 
The aim of our study was to evaluate electrical stimulation of the pelvic floor muscles prior to radical retropubic prostatectomy to accelerate the recovery of continence.

\section{MATERIALS AND METHODS}

Patients with prostate cancer (stage T2) and candidates for RPP who were referred for treatment at the Pelvic Surgery Department of A.C. Camargo Hospital were eligible for the study. Exclusion criteria included: radiotherapy (previous or after RPP); previous transurethral resection; pre-existing neurological disease; urinary fistula after RPP; prolonged indwelling urethral catheterization (more than 15 days); clinical situations that rendered the patient unsuitable for surgical procedure; failure to attend all PFMR or electrical stimulation sessions; loss of follow-up and desistance. The surgical intervention (RPP) was performed by four highly skilled and experienced surgeons and included nerve-sparring technique, according to Walsh.

\section{Outcome evaluation}

After approval by the ethical committee and internal review board, 58 consecutive males were included in this analysis. All subjects received and signed an informed consent form. The patients were randomized (computer-generated list using Research Randomizer, v4) and divided into 3 groups: control (only verbal instructions to contract the perineum); Kegel exercises alone; and electrical stimulation plus Kegel exercises.

The electrical stimulation (ES) group underwent ten preoperative physiotherapy sessions, with variable frequency (respecting scheduled surgery), using electrical stimulation and rectal pelvic exercises.

Electrical stimulation of this group was conducted with the Phenix equipment (VIVALTIS $^{\circledR}$ ) via rectal probe length of approximately 12 $\mathrm{cm}$, width $2.5 \mathrm{~cm}$ and approximate weight $04 \mathrm{~g}$.

The parameters used included parameters for muscle strengthening, to tonic fibers and phasic fibers:

To tonic fibers: Frequency: $20 \mathrm{~Hz}$ (Hertz); Pulse Width: 700us (microseconds),
Rise Time: 02 seconds Descent time: 02 seconds Working Time: 06 seconds Rest Time: 06 seconds. Intensity was used to determine the visible contraction of the pelvic floor. The duration of the stimulation was 10 minutes.

To phasic fibers: Frequency: $65 \mathrm{~Hz}$; Pulse Width: 150us, Rise Time: 02 seconds; Descent time: 02 seconds Working Time: 06 seconds Rest Time: 18 seconds. It was also used to determine the intensity visible contraction of the pelvic floor. The duration of the stimulation was 05 minutes.

The electrical stimulation group, in the same preoperative sessions, also performed five (5) types of exercises to contract the pelvic floor muscles: consecutive contractions of pelvic floor muscles for 5 seconds in dorsal decubitus (10 times), in the same position with the waist elevated (10 times), lying down with legs adduction against a plastic ball (10 times), and tenfold exercises standing and flexing the hips to approximately $60^{\circ}$.

The exercise group performed 10 (ten) preoperative physiotherapy sessions, with variable frequency (respecting scheduled surgery), using only the pelvic exercises. The exercises were exactly the same exercises of the electrical stimulation group, already described above.

The control group did not perform any type of therapeutic intervention in the preoperative period. The patients in this group were examined only once, before the surgery, when the evaluation was performed and when they received information about the anatomy of the prostate region (as in the other groups).

PFMR was performed in the preoperative period by the same physiotherapist (C.E.L.). All patients were then evaluated after RPP at 1, 3, and 6 months by 1 hour pad test, International Consultation on Incontinence Questionnaire- Short Form (ICIQ-SF), and the Medical Outcomes Study 36Item Short Form Health Survey (SF-36). No patient received PFMR postoperatively.

The 1 hour pad test was the primary outcome measure and was administered according to the International Continence Society (ICS). During the test, the patient was instructed to drink $500 \mathrm{~mL}$ of water, wait in the seated position for 30 minutes, walk, and do some exercises for another 30 minutes. 
The ICIQ-SF and SF-36 were considered secondary outcome measures and were self-administered. Possible doubts were solved with a different physiotherapist (T.R.R.).

\section{Statistical analysis}

The groups were compared by chi-square association test (for qualitative variables) and Kruskal-Wallis test (for quantitative variables). Comparisons of the SF-36, ICIQ-SF, and pad test scores between the groups during the follow-up period were made by two-way analysis of variance (ANOVA), in which 1 factor was a repeated measurement (month) and the other was an independent factor (group).

When there was a significant difference, post hoc Tukey HSD test was used to detect the difference. Differences between groups were considered, whereas within-group differences were disregarded. Odds ratios of the groups at each assessment $(1,3$, and 6 months after the operation) were also calculated to determine the likelihood of developing urinary incontinence. In the pad test, the cutoff point for continence was $\leq 2$ grams and $>2$ grams for incontinence.

In all analyses, differences were significant at $p<0.050$. The statistical analyses were performed using Statistica, version 7 (for ANOVA) and SPSS, version 16.0 (for all other analyses).

\section{RESULTS}

Nine men were excluded during the evaluation ( 2 for failing to attend all sessions, 2 due to desistance, 1 adjuvant radiotherapy, 1 postoperative urethral stenosis, 1 urinary fistula, 1 unsuitable for surgery due to cardiovascular risk, and 1 inadequate follow-up). Thus, 49 remained eligible for the study (15 in Group 1; 17 in Group 2; 17 in Group 3). The mean age of the patients was similar $(\mathrm{p}=0.556)$ in all groups (Group 1: $64 \pm 8$ years; Group 2: $62 \pm 7$ years; Group 3: $60 \pm 8$ years).

There were no significant differences between groups with respect to clinical and demographic data. Table- 1 shows baseline characteristics of the groups, regarding the qualitative variables.
The pad test (Table-2 and Figure-1) showed no significant difference between the 3 groups at first, third, and sixth months of follow-up ( $p$ > 0.05). Based on the odds ratios (ORs) between groups, there was no significant difference ( $p$ > 0.05), with a 95\% confidence interval. Using a cutoff of 2 grams, the ORs between Groups 1 and 2 and between Groups 1 and 3 were 1.2 and 0.71 at 1 month, 1.14 and 1.14 at 3 months, and 1.39 and 2.71 at the end of the study (Month 6), respectively.

There was no significant difference in ICIQ-SF score between the 3 groups at 1, 3, and 6 months of follow-up ( $p>0.05)$ (Table-3).

There were no differences between groups on the various domains of the SF-36 ( $p>0.05$ ).

\section{DISCUSSION}

Urinary control usually recovers gradually during the first year after RPP (10). However, even temporary UI can negatively affect one's quality of life and delay his return to social and professional activities.

Previous studies have focused on PFMR as a method to anticipate adequate urinary control after RPP, most of which reported better results when PFMR was used after RPP. Unfortunately, the optimal start and stop points, modality of PFMR, and duration and frequency of the treatment remain unknown.

Filocamo et al. (4) analyzed 300 consecutive patients who were randomized into 2 groups. One hundred fifty men were referred to a physiotherapist for pelvic exercises, and another 150 individuals were not given formal instructions for PFMR. Nineteen percent of the treated group achieved adequate continence during the first month following RPP, rising to 95\% after 6 months. In the control group, 8\% reported good urinary control at the first month versus $65 \%$ after 6 months.

Ribeiro et al. (6) also recently described good results in 26 patients who were treated with biofeedback-pelvic muscle training once per week for 3 months compared with a control group (28 men) who received only verbal instructions. At 12 months, $96 \%$ of patients in the biofeedback-trained 
Table 1 - Comparison between groups according to qualitative variables control $(\mathrm{N}=49)$.

\begin{tabular}{|c|c|c|c|c|c|}
\hline Variable & Category & & Group & & $P$ \\
\hline & & $\begin{array}{l}\text { Control } \\
\text { N (\%) }\end{array}$ & $\begin{array}{c}\text { Exercises } \\
\mathrm{N}(\%)\end{array}$ & $\begin{array}{c}\text { Electrical stim. } \\
N(\%)\end{array}$ & (火2) \\
\hline \multirow[t]{2}{*}{ Gleason } & 6 & $10(66,7)$ & $13(76,5)$ & $11(64,7)$ & 0,730 \\
\hline & $7-9$ & $5(33,3)$ & $4(23,5)$ & $6(35,3)$ & \\
\hline \multirow[t]{2}{*}{ Systemic Arterial Hipertension } & No & $5(33,3)$ & $12(70,6)$ & $11(64,7)$ & 0,077 \\
\hline & Yes & $10(66,7)$ & $5(29,4)$ & $6(35,3)$ & \\
\hline \multirow[t]{2}{*}{ Use of diuretics } & No & $8(53,3)$ & $14(82,4)$ & $13(76,5)$ & 0,164 \\
\hline & Yes & $7(46,7)$ & $3(17,6)$ & $4(23,5)$ & \\
\hline \multirow[t]{2}{*}{ Heart disease } & No & $13(86,7)$ & $17(100)$ & $16(94,1)$ & 0,291 \\
\hline & Yes & $2(13,3)$ & 0 & $1(5,9)$ & \\
\hline \multirow[t]{2}{*}{ Diabetes } & No & $13(86,7)$ & $13(76,5)$ & $17(100)$ & 0,111 \\
\hline & Yes & $2(13,3)$ & $4(23,5)$ & 0 & \\
\hline \multirow[t]{2}{*}{ Respiratory disease } & No & $14(93,3)$ & $16(94,1)$ & $17(100)$ & 0,571 \\
\hline & Yes & $1(6,7)$ & $1(5,9)$ & 0 & \\
\hline \multirow[t]{2}{*}{ Smoking } & No & $14(93,3)$ & $16(94,1)$ & $13(76,5)$ & 0,213 \\
\hline & Yes & $1(6,7)$ & $1(5,9)$ & $4(23,5)$ & \\
\hline \multirow[t]{2}{*}{ Performs Physical Exercises } & No & $8(53,3)$ & $11(64,7)$ & $8(47,1)$ & 0,578 \\
\hline & Yes & $7(46,7)$ & $6(35,3)$ & $9(52,9)$ & \\
\hline \multirow[t]{2}{*}{ Urinary loss preoperatively } & No & $12(80)$ & $14(82,4)$ & $16(94,1)$ & 0,464 \\
\hline & Yes & $3(20)$ & $3(17,6)$ & $1(5,9)$ & \\
\hline Other Cancer & No & 15 & 17 & 17 & $@$ \\
\hline Total & & $15(100)$ & $17(100)$ & $17(100)$ & \\
\hline
\end{tabular}

@: statistical test was not done because not all responded 
Table 2 - Comparison of pad test scores between groups during follow-up.

\begin{tabular}{lcccc}
\hline \multicolumn{5}{c}{ Groups } \\
\hline Period & $\begin{array}{c}\text { Control } \\
(\mathrm{N}=15)\end{array}$ & Exercises $\mathrm{N}=(17)$ & $\begin{array}{c}\text { Electrical Stimulation } \\
(\mathrm{N}=17)\end{array}$ & $\mathrm{p}^{*}$ \\
\hline Mean $(\mathrm{sd})$ & Mean $(\mathrm{sd})$ & Mean $(\mathrm{sd})$ & $>0.05$ \\
\hline 1 month & $17.6(38.5)$ & $29.5(35.8)$ & $25.5(35.4)$ & $>0.05$ \\
3 months & $14.3(34.4)$ & $11.8(28.4)$ & $9.6(18.8)$ & $>0.05$ \\
\hline months & $5.5(14.16)$ & $25.3(59.0)$ & $4.35(7.3)$ & \\
\hline
\end{tabular}

Figure 1 - Comparison of pad test results between groups during follow-up.

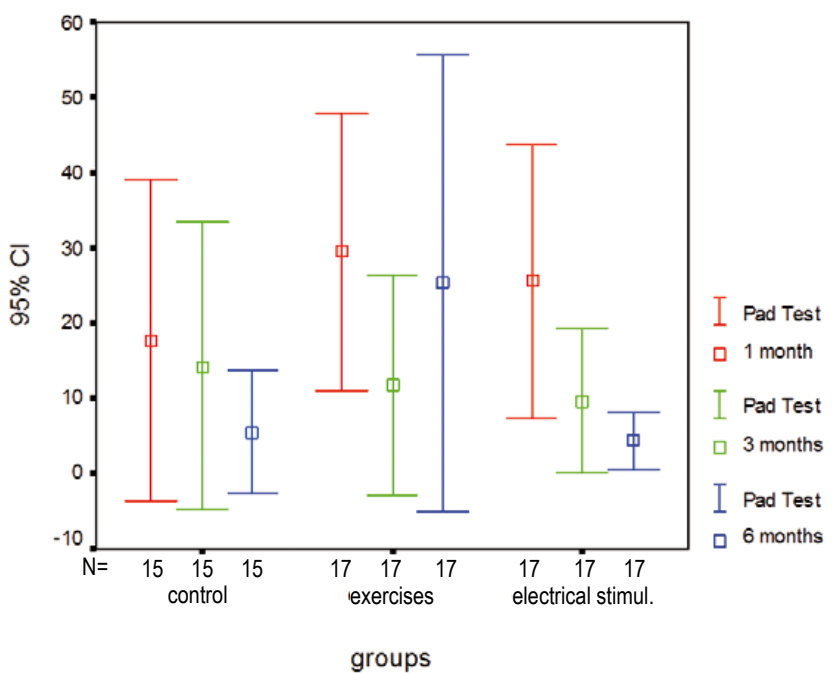

group were continent versus $75 \%$ in the verbal instruction group. They also described a short period of incontinence immediately after RPP.

Few studies have examined PFMR before RPP. Although Burgio et al. (11) noted an improvement in continence and a decreased time to achieve urinary control in patients who attended one session of assisted biofeedback pelvic floor training and performed exercises at home, other groups failed to describe any benefits of PFMR exclusively in the preoperative period.

Considering the possibility that chronic electrical stimulation of tonic and phasic myofibers increases muscle strength, we also evaluated preoperative electrical stimulation of pelvic floor muscles using a rectal probe, comparing this method with Kegel exercises without biofeedback and with a control group that received only verbal instructions. The primary outcome was the 1 hour pad test score; quality of life questionnaires (ICIQ-SF score and SF-36) were used as secondary measures. Neither variable differed, and the social and physical aspects of the SF-36 were unaffected by PFMR. The ICIQ-SF revealed no changes in the impact of incontinence on quality of life between the 3 groups, reinforcing the poor results of PFMR regarding this area.

These data confirm the findings of previous groups with regard to PFMR in the preoperative period and support that PFMR is effective only when used postoperatively. Although PFMR might be unnecessary before the striated sphincter fibers have been manipulated, Parekh et al. (12) demonstrated good results with PFMR before and after the surgical procedure. Further studies are needed to determine whether preoperative and postoperative PFMR is more effective than PFMR only after RRP. 
Table 3 - Comparison of ICIQ-SF scores between groups during follow-up.

\begin{tabular}{lcccc}
\hline \multicolumn{5}{c}{ Groups } \\
\hline Period & $\begin{array}{c}\text { Control } \\
(\mathrm{N}=15)\end{array}$ & $\begin{array}{c}\text { Exercises } \\
(\mathrm{N}=17)\end{array}$ & $\begin{array}{c}\text { Electrical stimulation } \\
(\mathrm{N}=17)\end{array}$ & $\mathrm{p}$ \\
\cline { 2 - 4 } & Mean (sd) & Mean $(\mathrm{sd})$ & Mean $(\mathrm{sd})$ & $>0.05$ \\
\cline { 2 - 3 } 1 month & $7.5(5.0)$ & $14(3.6)$ & $9.6(6.3)$ & $>0.05$ \\
6 months & $5.4(5.2)$ & $6.9(5.8)$ & $7.2(6.4)$ & $>0.05$ \\
\hline
\end{tabular}

\section{CONCLUSIONS}

Preoperative rectal electrical stimulation has no impact on continence status in patients who undergo radical retropubic prostatectomy regarding urinary leakage and quality of life.

\section{FINANCIAL SUPPORT}

Sao Paulo State Foundation for Research Support - FAPESP (number 08/54585-1)

\section{CONFLICT OF INTEREST}

None declared.

\section{REFERENCES}

1. Liu L, Coker AL, Du XL, Cormier JN, Ford CE, Fang S: Longterm survival after radical prostatectomy compared to other treatments in older men with local/regional prostate cancer. J Surg Oncol. 2008; 97: 583-91.

2. Van Kampen M, De Weerdt W, Van Poppel H, De Ridder $D$, Feys $H$, Baert L: Effect of pelvic-floor re-education on duration and degree of incontinence after radical prostatectomy: a randomised controlled trial. Lancet. 2000; 355: 98-102.
3. Moore KN, Valiquette L, Chetner MP, Byrniak S, Herbison GP: Return to continence after radical retropubic prostatectomy: a randomized trial of verbal and written instructions versus therapist-directed pelvic floor muscle therapy. Urology. 2008; 72: 1280-6.

4. Filocamo MT, Li Marzi V, Del Popolo G, Cecconi F, Marzocco M, Tosto A, et al.: Effectiveness of early pelvic floor rehabilitation treatment for post-prostatectomy incontinence. Eur Urol. 2005; 48: 734-8.

5. Mariotti G, Sciarra A, Gentilucci A, Salciccia S, Alfarone A, Di Pierro $G$, et al.: Early recovery of urinary continence after radical prostatectomy using early pelvic floor electrical stimulation and biofeedback associated treatment. J Urol. 2009; 181: 1788-93.

6. Ribeiro LH, Prota C, Gomes CM, de Bessa J Jr, Boldarine MP, Dall'Oglio MF, et al.: Long-term effect of early postoperative pelvic floor biofeedback on continence in men undergoing radical prostatectomy: a prospective, randomized, controlled trial. J Urol. 2010; 184: 1034-9.

7. Bauer RM, Bastian PJ, Gozzi C, Stief CG: Postprostatectomy incontinence: all about diagnosis and management. Eur Urol. 2009; 55: 322-33.

8. Bales GT, Gerber GS, Minor TX, Mhoon DA, McFarland JM, Kim HL, et al.: Effect of preoperative biofeedback/pelvic floor training on continence in men undergoing radical prostatectomy. Urology. 2000; 56: 627-30.

9. Tobía I, González MS, Martínez P, Tejerizo JC, Gueglio G, Damia 0, et al:: Randomized study on urinary continence after radical prostatectomy with previous kinesic perineal physiotherapy. Arch Esp Urol. 2008; 61: 793-8. 
10. Van Kampen M, De Weerdt W, Van Poppel H, Baert L: Urinary incontinence following transurethral, transvesical and radical prostatectomy. Retrospective study of 489 patients. Acta Urol Belg. 1997; 65: 1-7.

11. Burgio KL, Goode PS, Urban DA, Umlauf MG, Locher JL, Bueschen A, et al.: Preoperative biofeedback assisted behavioral training to decrease post-prostatectomy incontinence: a randomized, controlled trial. J Urol. 2006; 175: 196-201; discussion 201.
12. Parekh AR, Feng MI, Kirages D, Bremner H, Kaswick J, Aboseif S: The role of pelvic floor exercises on post-prostatectomy incontinence. J Urol. 2003; 170: 130-3.

Correspondence address: Dr. Carlos Alberto Ricetto Sacomani Hospital A.C. Camargo Rua Antonio Prudente, 211, Liberdade São Paulo, SP, Brazil E-mail: drsacomani@gmail.com 